\title{
Thermal cracking resistance of stacking concrete blocks
}

\author{
Albina Shaibakova ${ }^{1,}$, , Kirill Semenov ${ }^{2}$, and Yurij Barabanshchikov ${ }^{3}$ \\ ${ }^{1}$ Department of Building Mechanics and Structural Engineering, Peter the Great St. Petersburg \\ Polytechnic University, 195251, St. Petersburg, Russia \\ ${ }^{2}$ Department of Building Mechanics and Structural Engineering, Peter the Great St. Petersburg \\ Polytechnic University, 195251, St. Petersburg, Russia \\ ${ }^{3}$ Construction of Unique Buildings and Structures Department, Peter the Great St. Petersburg \\ Polytechnic University, 195251, St. Petersburg, Russia
}

\begin{abstract}
In massive concrete structures there is a danger of temperature cracks. One of the measures to get rid of these type of cracks is the breakdown of an array into concreting blocks. In this paper, we consider the provision of thermal crack resistance of a massive concrete structure during the construction period. A comparative analysis of the thermally stressed state of the structure erected by one and two blocks in height is carried out. The influence of the overlap intervals of the concrete block in the calculations of thermal crack resistance was evaluated. Thermal crack resistance is evaluated by the deformation criterion. The authors found that the breakdown of the concrete structure into concreting blocks reduces the elongation deformations by $37 \%$. The results show that increasing the overlap interval of a concrete block more effectively ensures thermal crack resistance of the structure.
\end{abstract}

\section{Introduction}

In massive concrete and reinforced concrete structures there is a danger of thermal cracking [1]. One of the reasons causing internal and surface temperature cracks are significant thermal tensile stresses. They result from the release of large amounts of heat during the reaction of cement with water.

By now, a large amount of research on the thermal stress state of massive concrete structures and the formation and kinetics of temperature cracks [2-3] has been done. The experience in studying the structure of concrete, its mechanical and strength properties has been gained [4-7]. Equations of the theory of heat conduction were obtained. These equations describe thermal processes occurring inside massive concrete structures [8], equations of mechanics of a deformable medium, which make it possible to obtain a reliable picture of thermal stress fields in monolithic concrete structures, taking into account creep [9-11], and aging of the material [13]. There was a transition to a mathematical modeling of the thermally

\footnotetext{
* Corresponding author: albinashaibakova@gmail.com
} 
stressed state of concrete structures [14-18], which makes it possible to predict the potential appearance of temperature cracks.

An assessment of the effect of the breakdown of a concrete structure on the concreting blocks in the calculations of thermal crack resistance was made by some authors earlier [1922]. But in these works, a calculation assessment of the thermally stressed state of the concrete mixtures used for the construction of hydraulic structures was made. Such mixtures have low heat dissipation, as for their manufacture cement with low consumption is used. In this paper, we considered an array erected from a concrete mix with a high consumption of cement and, consequently, with high heat release. Such mixtures are used for the construction of base plates of nuclear power plants and other critical buildings and structures.

As is well known, the concreting of massive concrete base plates and other massive structures, for a variety of technological and production considerations, is preferably done in a single block in height [23-26]. However, this leads to a significant heating of the array, due to an exothermic reaction during the hardening of the concrete mix. The resulting significant uneven distribution of temperature over the height of the plate leads to the occurrence of dangerous tensile stresses (and, accordingly, elongation deformations), first on the surface of the plate, and then in its central zones [27,28].

There are many measures to ensure the thermal crack resistance of concrete and reinforced concrete massive structures [29-31]. One of the methods of reduction of temperature cracks is the breakdown into concreting blocks.

The purpose of this paper is to evaluate the effect of breaking a massive block into concreting blocks, as well as assessing the impact of the overlap interval of concrete blocks in the calculations of thermal crack resistance.

\section{Methods}

In this paper, a concrete massive structure with a thickness of 2 meters made of B35 concrete with a cement consumption of $340 \mathrm{~kg} / \mathrm{m}^{3}$ was considered. The array rests on a layer of concrete bed B12.5 on a soil base. The thermophysical characteristics of concrete B35 are taken as follows: the thermal conductivity of concrete is $\lambda=2.67 \mathrm{~W} /\left(\mathrm{m} \cdot{ }^{0} \mathrm{C}\right)$, the specific heat capacity $\mathrm{c}=1.0 \mathrm{~kJ} /\left(\mathrm{kg} \cdot{ }^{\circ} \mathrm{C}\right)$. The air temperature is $20^{\circ} \mathrm{C}$, the concrete mix is $20^{\circ} \mathrm{C}$.

The upper surface of the plate is open - it does not have special thermal insulation. The massive structure is concreted in one block in height - in the first case and in two blocks in height - in the second case. It was assumed that the massive structure is divided into concreting blocks of the same height.

The equation proposed by Zaporozhets I.D. describes the process of heat generation in both cases. The parameters of the equation are obtained empirically:

$$
\mathrm{Q}(\tau)=\mathrm{Q}_{\max }\left[1-\left(1+\mathrm{A}_{\mathrm{T}} \tau\right)\right]^{-\frac{1}{\mathrm{~m}-1}}
$$

where $Q_{\max }$ is the limit to which the heat dissipation of concrete tends;

$A_{T}$ is the coefficient of heat release rate, characterizing the rate of heat release at a constant temperature $\mathrm{T}$;

$m$ - the order of the hydration reaction on water, which for Portland cement depending on the type of additives used is from 1.1 to 2.3 .

The influence of the hardening temperature on the heat dissipation of concrete is carried out using the temperature function:

$$
\mathrm{f}_{\mathrm{T}}=2^{\frac{T_{1}-T_{2}}{\varepsilon}}
$$

where $\varepsilon$ is the characteristic temperature difference. When $T_{1}-T_{2}=\varepsilon$, the temperature function will be, $f_{T}=2$, it means when the temperature rises by $\varepsilon$ degrees, the heat generation rate will increase by 2 times. 
The "reduced time" hypothesis used in this work allows us to accept that at moments of equal heat release $Q_{1}=Q_{2}$, where $Q_{1}$ and $Q_{2}$ are the heat release values at temperatures, respectively, $T_{1}$ and $T_{2}$, the ratio of heat release rates, as well as the corresponding terms $\tau_{2}$ and $\tau_{1}$ remains constant throughout the process.

At the same time, the specific heat release of cement $q=Q / C=482.2 \mathrm{~kJ} / \mathrm{kg}$; heat release growth rate coefficient at $20^{\circ} \mathrm{C} A_{20}=2.12 \cdot 10^{-6} \mathrm{~s}^{-1}$. Cement consumption in concrete was $\mathrm{C}$ $=340 \mathrm{~kg} / \mathrm{m}^{3}$. These parameters of the heat generation process were determined experimentally.

With the help of the software "TERM", which was developed at the Department of Building Mechanics and Structural Engineering of Peter the Great St. Petersburg Polytechnic University in this paper [1], the thermal stress state of the array was calculated, which was erected with one or two blocks in height. The calculation was made according to the P. Vasilyev's deformation criterion $[9,10]$. This criterion assesses the thermal crack resistance of the structure on the basis that the elongation deformations of concrete should not exceed the ultimate tensile properties of concrete $[9,10]$.

Since the height of the array is significantly less than its planned size, in this work it is possible to move to a one-dimensional design scheme. In this case, the voltage and temperature will be functions of the same vertical coordinate.

\section{Results and Discussion}

\subsection{Investigation of the effect of breaking down a concrete massive block into concreting blocks}

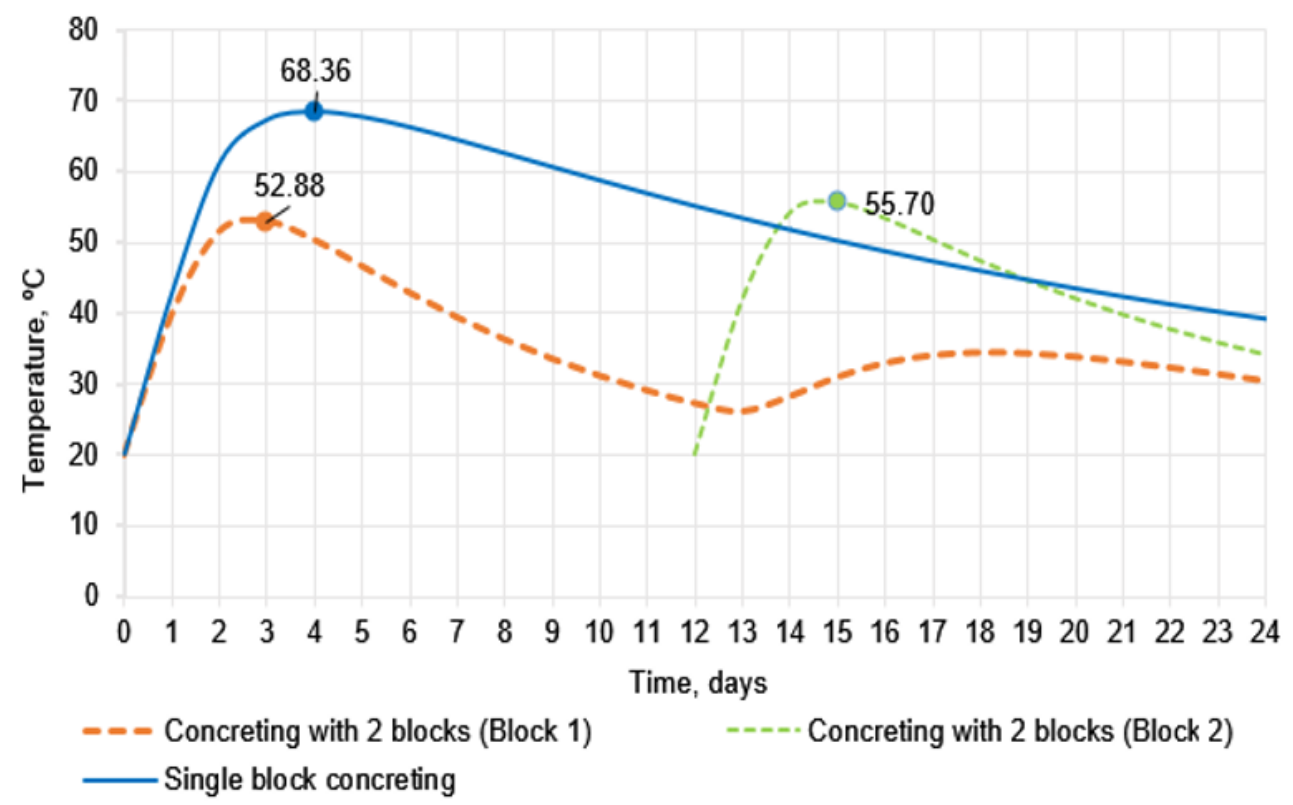

Fig. 1. The graph of temperature changes in the center of the block. 


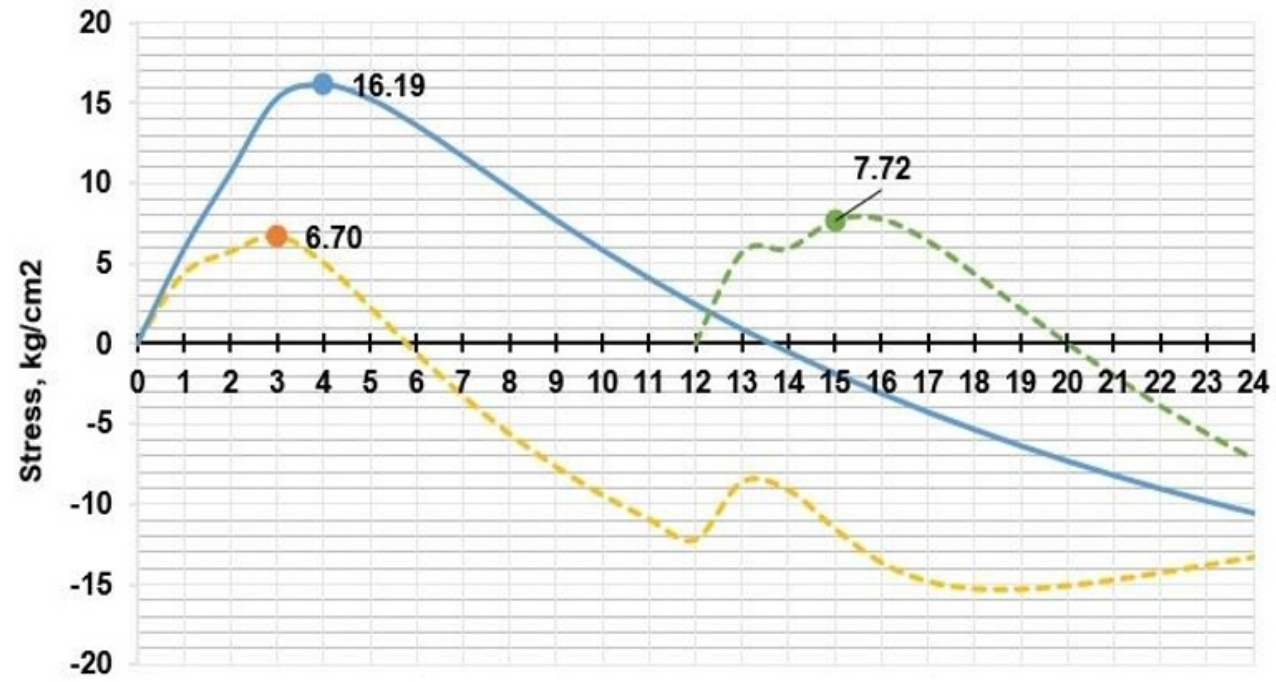

Time, days

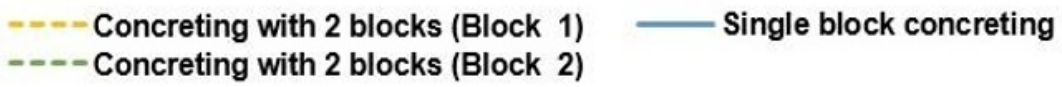

Fig. 2. The graph of stress changes on the top of the block.

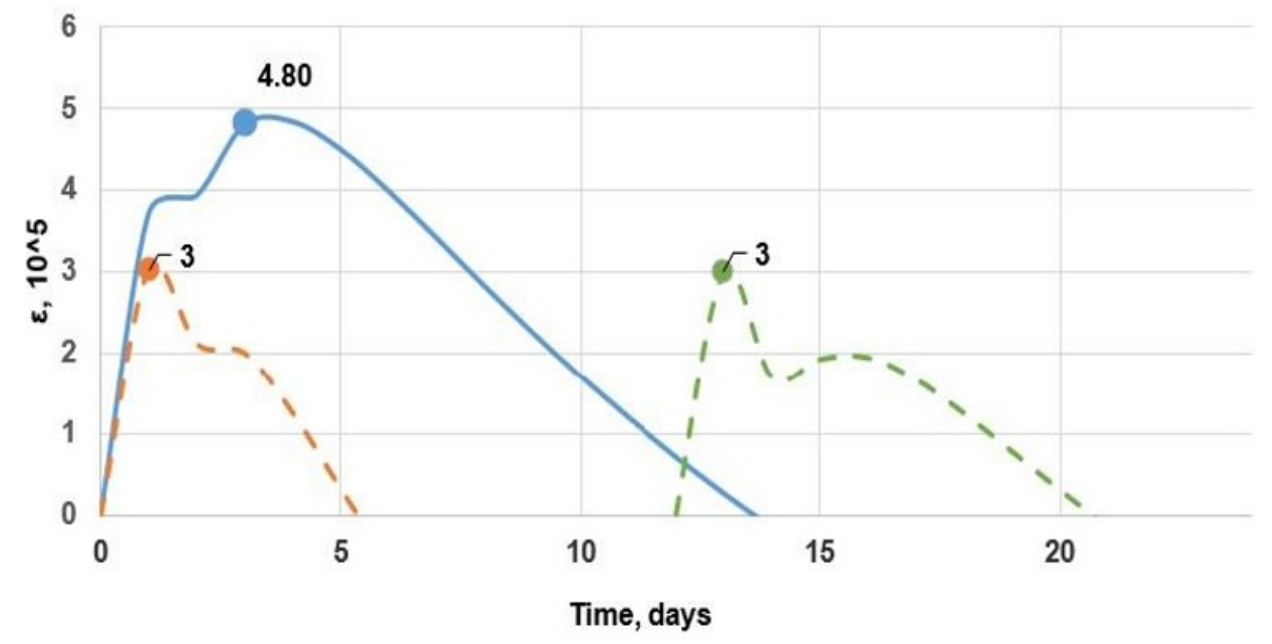

\section{__ Single block concreting \\ - - Concreting with two blocks (Block 2)}

- - Concreting with two blocks (Block 1)

Fig. 3. Graph of elongation deformations.

Analysis of the results shows the following:

1. When the massive structure is concreting with one block, the maximum temperature is reached on the 4th day from the moment of laying the mixture and is equal to $68.36^{\circ} \mathrm{C}$; when the massive structure is concreting with two blocks, the maximum temperature is reached in the center of the block for 15 days and equal to $55.70{ }^{\circ} \mathrm{C}$ (Fig. 1) 
2. On the 4th day at the time of the greatest exothermic heating during the concreting with one block in height, there is a maximum tensile stress of $16.19 \mathrm{~kg} / \mathrm{cm}^{2}$. When the massive structure is concreting with two blocks, the greatest stress is observed for 15 days and is equal to $7.72 \mathrm{~kg} / \mathrm{cm}^{2}$ (Fig. 2).

The breakdown of the massive structure into concreting blocks leads to a decrease of tensile stresses of the massive concrete structure by $52.32 \%$. Also in the first case, a dangerous stretch occurs at an earlier time (shift by 10 days). Fig. 3 illustrates the changes in elongation deformations. When the massive block is concreting with 2 blocks in height a decrease in the maximum elongation deformation is observed and equal $37 \%$.

\subsection{The study of the effect of the overlap intervals of a concrete block in the calculations of thermal crack resistance}

Consider the concreting of two blocks in height with a different interval of overlap of Block 1 (5-7-10-12 days).

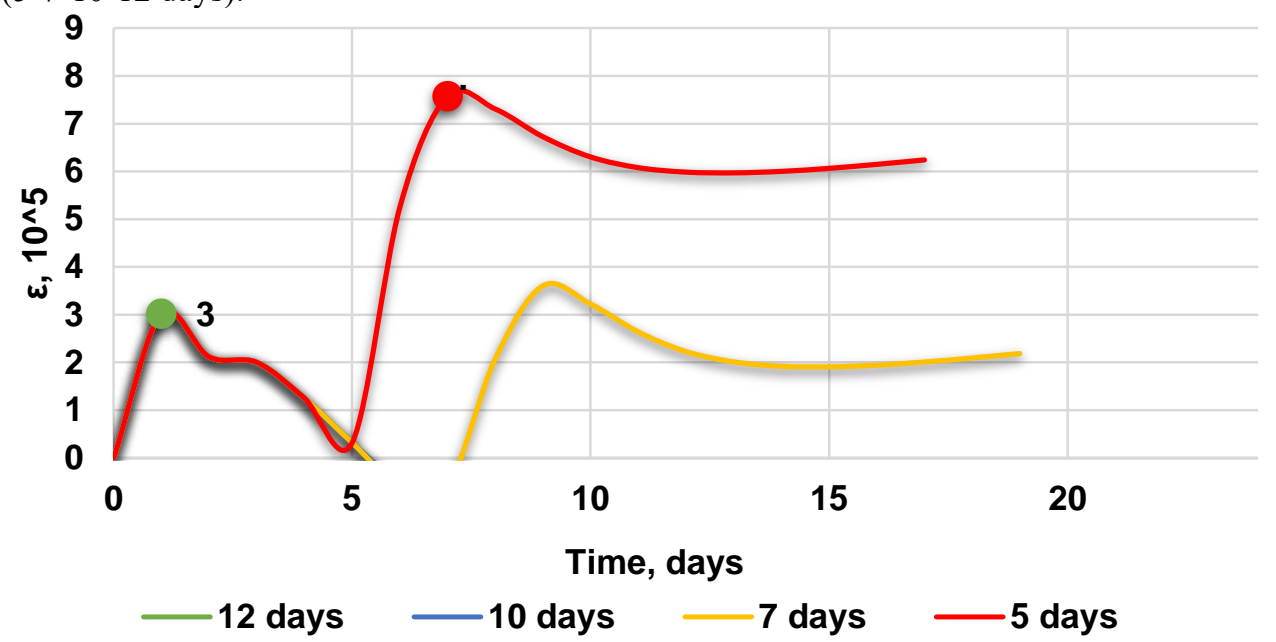

Fig. 4. The elongation deformations of Block 1

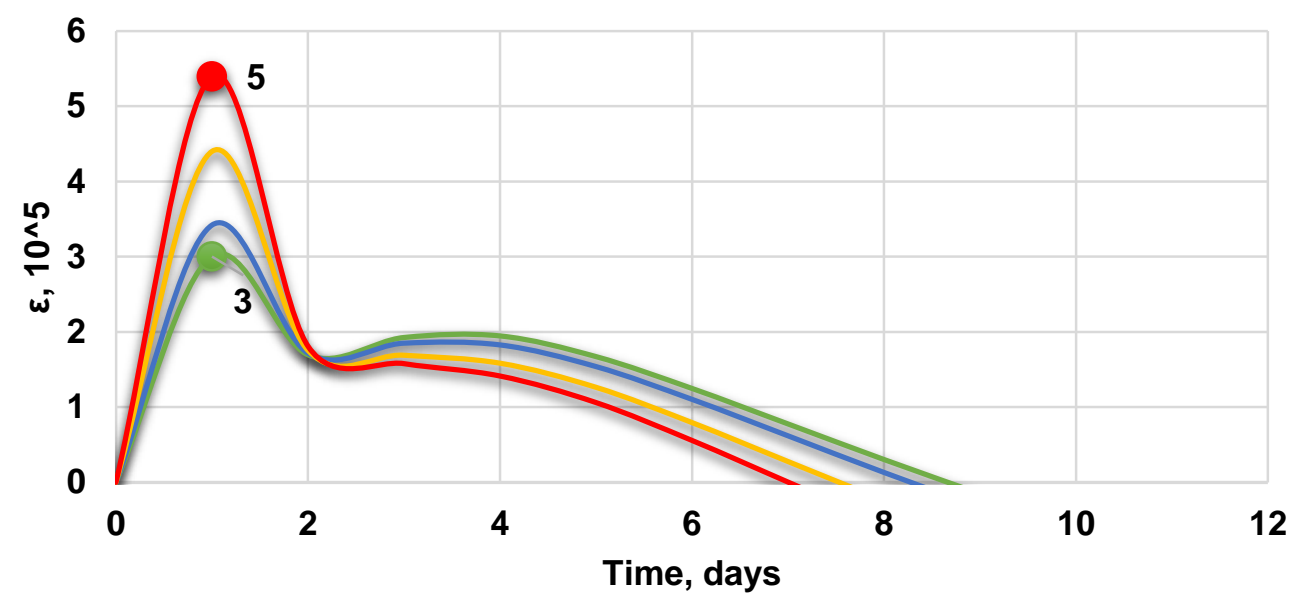

-12 days -10 days $\longrightarrow$ days -5 days

Fig. 5. The elongation deformations of Block 2 
Analysis of the results shows the following:

There is the same nature of the change in elongation deformations at different overlap times of the concrete block in Block 1 and Block 2. In Block 1, elongation deformations decrease with increasing interval of concreting (decrease by $60.11 \%$ in elongation deformations on the top of block), in Block 2 - also increase (decrease by $44.44 \%$ in elongation deformations on the top of block). The results obtained are close to field data [2].

\section{Conclusions}

1. In the case of concreting the structure with two blocks in height, the maximum temperature inside the block decreases by $18.5 \%$.

2. The breakdown of the massive structure into concreting blocks leads to a decrease of tensile stresses of the massive concrete structure by $52.32 \%$.

3. The reducing the elongation deformations compared to concreting single block in height was $37 \%$.

4. With an increase in the overlap interval of the first concrete block, a decrease in elongation deformations on the block surface by $60.11 \%$ (in the first block) and by $44.44 \%$ (in the second block) is observed, which also provides more effective the thermal crack resistance of the massive concrete structure.

\section{References}

1. K. Semenov, Temperature and thermal stressed state of concreting blocks in a high pressure shell during the building period (LPI im. M.I.Kalinina, Leningrad, 1990)

2. K. Semenov, Yu. Barabanshchikov., App. Mech. Mat., 725 -726 (2015)

3. A. Bushmanova, N. Videnkov, K. Semenov, Yu. Barabanshchikov, A. Dernakova, V. Korovina, Mag. Civ. Eng., 3(71) (2017)

4. Yu. Barabanshchikov, K. Semenov, Pow. Tech. and Eng., 41(4) (2007)

5. M. Dudin, N. Vatin, Yu. Barabanshchikov, Mag. Civ. Eng., 2(54) (2015)

6. N. Vatin, Yu. Barabanshchikov, M. Komarinskiy, S. Smirnov, Mag. Civ. Eng., 4(56) (2015)

7. R. Ibragimov, S. Pimenov, Mag. Civ. Eng., 2(62) (2016)

8. A. Schackowa, C. Effting R., I. Z. Patruni, F. Vicenzi, C. Kramel, App. Therm. Eng., 100 (2016)

9. P. Vasilyev, Yu. Kononov, Izv. VNIIG, 75 (1964)

10. P.Vasilyev, Izv. VNIIG, 64 (1952)

11. I. Korotchenko, E. Ivanov, S. Manovitskiy, V. Borisova, K. Semenov, Yu. Barabanshchikov, 1(69) (2017)

12. W. Shengxing, H. Donghui, J. Therm. An. and Calorim., 34(2) (2011)

13. M. Larson, Thermal crack estimation in early age concrete -models and methods for practical application (Lulea University of Technology, Lulea, 2003)

14. M.R. Eduardo, Cem. and Con. Terminology, 82 (2000)

15. R.D. Borst, A.H. Boogaard, J. Eng. Mech., 5 (1994)

16. J. Rots, Computational modelling of concrete fracture (Delft University of Technology, Delft, 1988)

17. M.N. Amin, J.S. Kim, Y. Lee, J-K. Kim, Cem. and Con. Res. 39(3) (2009) 
18. M.S. Jaafar, Adv. in Eng. Software, 38 (2007)

19. H.-J. Chen, H.-S. Peng, Y.-F. Chen, J. Chinese In. Eng., 27(3) (2004)

20. V. Korsun, N. Vatin, A. Franchi, A. Korsun, P. Crespi, S. Mashtaler, Proc. Eng., 117 (2015)

21. V. Plevkov, A. Malinovskij, I. Baldin, Vest. tom. gos. arh.-str. un. 2(39) (2013)

22. M. Ishikawa, J. Com. and Str., 40(2) (1991)

23. A. H. Malkawi, J. Per. Constr. Fac., 17(4) (2003)

24. J. M. de Arauujo, A. M. Awruch, Com. and Str., 66 (1998)

25. H. W. Xie, Y. L. Chen. Adv. in Eng. Software., 36 (2005)

26. V. Bredyuk, Thermal stress state of concrete massifs of hydraulic structures during the construction period (influence of variable physicomechanical characteristics) (LPI im. M.I.Kalinina, Leningrad, 1988)

27. A. Struchkova, Y. Barabanshchikov, K. Semenov, A. Shaibakova, Mag. Civ. Eng., 2(78) (2018)

28. J. Gajda, M. Vangeem, Con. Int., 38(11) (2002)

29. Z. Zhang, X. Zhang, X. Wang, T. Zhang, X. Zhang, App. Mech. and Mat., 94 -96 (2011)

30. Yu. Barabanshchikov, S. Belyayeva, I. Arkhipov, M. Antonova, A. Shkolnikova, K. Lebedeva, Mag. Civ. Eng., 6(74) (2017)

31. A. Tsybin, Izv. VNIIG, 237 (2000) 